\title{
MENUJU ASEAN POLITICAL AND SECURITY COMMUNITY: KRITIK DAN TANTANGAN POLITIK HUKUM HAM INDONESIA DALAM REGIONALISME HAM ASEAN
}

(Towards ASEAN Political and Security Community: Critics and Challenges on Indonesia's Human Rights Law Politics Under Asean Human Rights Regionalism)

\author{
Harison Citrawan \\ Badan Penelitian dan Pengembangan HAM, Kementerian Hukum dan HAM \\ Email: h.citrawan@hotmail.com
}

Naskah diterima: 4 Juli 2014; revisi: 29 Agustus 2014; disetujui: 29 Agustus 2014

\begin{abstract}
Abstrak
Tulisan ini mencoba menganalisis regionalisme hak asasi manusia (HAM) di kawasan Asia Tenggara dari sudut pandang politik hukum HAM Indonesia. Secara khusus, analisis akan dilakukan pada bagaimana peluang dan tantangan politik hukum HAM nasional dalam mewujudkan mekanisme perlindungan HAM regional, serta bagaimana gambaran interaksi ideal antara mekanisme perlindungan HAM di tingkat regional dengan nasional. Menggunakan pendekatan analisis rezim dan dipadukan dengan konsep kepatuhan hukum, tulisan ini mengajukan proposisi bahwa regionalisme HAM dalam kerangka kerja ASEAN akan sia-sia apabila tidak diikuti dengan tingkat kepatuhan hukum (legal compliance) negara-negara anggota ASEAN terhadap norma dan prinsip HAM di tingkat domestik. Dalam konteks politik hukum HAM nasional, terdapat setidaknya tiga dimensi tantangan yang perlu diperhatikan dalam masa mendatang yang meliputi: desentralisasi, diskursus militer-HAM, dan skeptisisme terhadap hukum HAM internasional. Tulisan ini menyimpulkan bahwa terdapat kebutuhan akan harmoni dalam reposisi politik hukum HAM baik di tingkat nasional dan regional, agar norma yang telah disepakati pada tingkat internasional dapat diimplementasikan dan diterjemahkan di tingkat regional, dan yang lebih penting lagi ialah agar regionalisme HAM ASEAN dapat memberi pengaruh terhadap domestikasi nilai dan prinsip HAM di Indonesia. Kata Kunci: regionalisme, politik hukum, hak asasi manusia
\end{abstract}

\section{Abstract}

This paper attempts to analyze human rights regionalism in ASEAN from Indonesia's national human rights politics perspective. In particular, an analysis will be taken on challenges and opportunities of the national human rights politics in establishing a stronger regional human rights mechanism, and how an ideal interaction between regional and national human rights mechanisms should be drawn. Using regime analysis approach and combined with legal compliance concept, this paper proposes that ASEAN human rights regime would be superfluous if it is not followed by member states' legal compliance upon human rights norms and principle in domestic level. In the context of national human rights politics, there are at least three challenging dimensions that ought to be considered in the future, namely: decentralization, human rights-military discourse, and international human rights law skepticism. This paper thus concludes that there is a need to harmonize the human rights politics in both national and regional level, so that any internationally accepted norms will be implemented and applied into ASEAN human rights regionalism, and equally important is to ensure that such a regionalism is capable in influencing human rights values and principles domestication in Indonesia.

Keywords: regionalism, legal politics, human rights 


\section{A. Pendahuluan}

Salah satu pokok tema dalam gagasan pembentukan ASEAN Political and Security Community (APSC) pada tahun 2015 adalah memastikan bekerjanya sebuah rezim hak asasi manusia dalam kerangka kerja ASEAN. ${ }^{1}$ Secara eksplisit, disebutkan dalam APSC blueprint bahwa negara-negara ASEAN sepakat untuk: 'promote political development in adherence to the principle of democracy, the rule of law and good governance, respect for and promotion and protection of human rights and fundamental freedoms as inscribe in the ASEAN Charter.' Komitmen tersebut secara eksplisit mengasumsikan bahwa prinsip demokrasi, supremasi hukum dan HAM menjadi landasan dan prioritas ASEAN sebagai sebuah organisasi regional. ${ }^{2}$ Lebih lanjut, perlu dipahami bahwa komitmen terkait tersebut perlu diposisikan sebagai bagian dari kerangka besar APSC yang memiliki tiga karakteristik kunci, meliputi: ${ }^{3}$ Pertama, A Rules-based Community of shared values and norms; Kedua, A Cohesive, Peaceful, Stable and Resilient Region with shared responsibility for comprehensive security; ketiga, A Dynamic and Outward-looking Region in an increasingly integrated and nterdependent world.

Dalam konteks tersebut, tulisan ini mencoba menganalisis regionalisme HAM di dalam
ASEAN dari sudut pandang politik hukum HAM Indonesia. Secara khusus, analisis akan dilakukan pada bagaimana peluang dan tantangan politik hukum HAM nasional dalam mewujudkan mekanisme perlindungan ham regional, serta bagaimana interaksi ideal antara mekanisme perlindungan ham di tingkat regional dengan nasional. Menggunakan regime analysis dan dipadukan dengan konsep kepatuhan hukum (legal compliance), tulisan ini mengajukan proposisi bahwa rezim regionalisme HAM di ASEAN akan sia-sia apabila tidak diikuti dengan tingkat kepatuhan hukum (legal compliance) negara-negara anggota ASEAN terhadap norma dan prinsip HAM pada tingkat domestik. Kesiasiaan tersebut dapat diidentifikasi sebagai tantangan pada masa mendatang, secara khusus tentang apakah regionalisme HAM dalam kerangka APSC dapat memengaruhi (dan pada derajat tertentu menekan) tingkat domestifikasi nilai-nilai HAM yang disepakati pada tingkat regional.

Adapun tulisan ini pertama-tama akan mendeskripsikan regionalisme perlindungan HAM sebagai sebuah tren komunitas internasional, dimana tujuan dan efektivitas kerja regionalisme tersebut, yang selalu didasarkan pada sebuah landasan hukum (misalnya dalam bentuk perjanjian internasional), selalu dapat diperdebatkan pada tataran praksis hubungan internasional. Perhatian khusus pada deskripsi 
tersebut akan difokuskan pada problematika panjang pembentukan mekanisme regional HAM ASEAN. Selanjutnya, penulis akan mencoba menggambarkan bagaimana kesiapan politik hukum HAM Indonesia dalam menghadapi regionalisme HAM dalam konteks APSC. Terakhir, tulisan ini mencoba untuk menerapkan analisis rezim agar memperoleh gambaran tentang peluang Negara Indonesia dalam upaya memastikan perlindungan HAM dalam regionalisme HAM di ASEAN.

Berangkat dari deskripsi pendahuluan tersebut, tulisan ini merumuskan pertanyaan utama yakni: Bagaimana kesiapan politik hukum HAM Indonesia terhadap regionalisasi HAM di kawasan Asia Tenggara, serta bagaimana kritik mekanisme regional HAM dalam ASEAN Intergovernmental Commission on Human Rights (AICHR) agar dapat berfungsi secara efektif dalam melindungi HAM di kawasan Asia Tenggara?

\section{B. Metode Penelitian}

Tulisan ini merupakan studi kualitatif dengan pengumpulan data melalui studi literatur, meliputi: sumber-sumber hukum baik nasional dan internasional, serta berbagai tulisan yang mendiskusikan tentang tiga hal pokok, yakni: ASEAN, regionalisme HAM, serta politik HAM Indonesia. Ketiga isu tersebut dipadukan untuk kemudian dianalisis dengan dua jalur (tracks) pemikiran yaitu: pertama, analisis deskriptif mekanisme HAM regional ASEAN dan kritik terhadap efektivitas mekanisme regional tersebut melalui analisis rezim secara institusional; dan kedua, analisis deskriptif politik hukum HAM Indonesia dan tantangan terhadap regionalisme HAM ASEAN. Kedua jalur pemikiran tersebut kemudian dihimpun ke dalam sebuah formula bagaimana di satu sisi, regionalisme HAM ASEAN dapat memengaruhi domestikasi dan kepatuhan (compliance) HAM di Indonesia, dan di sisi lain, bagaimana politik hukum HAM Indonesia perlu disiapkan dalam menghadapi dan mewarnai mekanisme HAM dalam kerangka kerja ASEAN.

\section{Pembahasan}

\section{Menuju Regionalisme HAM Asia Tenggara}

Paska Perang Dunia Kedua, perkembangan 'normativitas' HAM bergerak dalam tiga lapisan, yakni pada tingkat internasional, regional, maupun nasional. Pada tingkat internasional, proliferasi pembentukan perjanjian HAM internasional serta organ-organ untuk memastikan pelaksanaan perjanjian tersebut nampak menjadi tren yang dominan dalam hubungan internasional, secara khusus dalam ruang lingkup Perserikatan BangsaBangsa. Pada tingkatan regional, proliferasi di atas juga ditemukan dalam praktik berbagai region negara-negara di beberapa belahan dunia, misalnya negara-negara Eropa di bawah wewenang Council of Europe membentuk European Convention of Human Rights pada tahun 1953, atau negara-negara yang tergabung dalam Organization of African Unity menyepakati diterbitkannya African Charter on Human dan Peoples' Rights pada tahun 1987. Sedangkan pada tingkat nasional, negara-negara mulai memasukkan HAM dalam konstitusi maupun peraturan-peraturan lainnya, serta membentuk beragam organ untuk menjamin dan mempromosikan perlindungan dan pemenuhan HAM pada tingkat domestik.

Secara khusus pada tingkat regional, mekanisme perlindungan HAM di tingkat kawasan tersebut pada prinsipnya bersifat independen dari mekanisme internasional 
yang berlaku di PBB. ${ }^{4} \mathrm{Hal}$ ini sangat beralasan mengingat Piagam PBB tidak secara eksplisit menyebutkan adanya kemungkinan pembentukan mekanisme perlindungan HAM regional. Namun demikian, seluruh mekanisme perlindungan HAM regional yang ada selalu mengacu pada norma yang telah disepakati pada tingkat internasional dan diinisasi oleh kerangka kerja PBB, terutama Universal Declaration of Human Rights. Dengan demikian, 'regionalisme' HAM, untuk menyebut upaya perlindungan HAM pada tingkat regional, dapat diasumsikan bersifat independen namun secara metodologis tidak dapat terlepas dari keberlakuan norma pada tingkat internasional (khususnya yang diterbitkan oleh PBB). Secara lebih spesifik, dorongan untuk regionalisme HAM juga tersurat dalam Vienna Declaration and Programme of Action 1993 yang menyatakan bahwa:

Regional arrangements play a fundamental role in promoting and protecting human rights. They should reinforce universal human rights standards, as contained in international human rights instruments, and their protection. The World Conference on Human Rights endorses efforts under way to strengthen these arrangements and to increase their effectiveness, while at the same time stressing the importance of cooperation with the United Nations human rights activities.

The World Conference on Human Rights reiterates the need to consider the possibility of establishing regional and sub-regional arrangements for the promotion and protection of human rights where they do not already exist. ${ }^{5}$

Dari Deklarasi tersebut, telah tersurat bahwa regional arrangements perlu diposisikan sebagai bentuk reinforcement atau penguatan standar HAM universal yang tertuang dalam berbagai instrumen HAM internasional. ${ }^{6}$

Pada tataran praktis, regionalisme HAM nampaknya menjadi pilihan negara-negara dengan dasar kesamaan kultur, ekonomi, politik, serta yang paling nyata kedekatan geografis. Dasar kesamaan tersebut dapat diasumsikan akan memudahkan negara-negara dalam sebuah kawasan untuk sepakat dalam pembentukan regionalisme HAM, serta secara politis, akan lebih mudah dalam melakukan koordinasi kebijakan terkait perlindungan dan promosi HAM. ${ }^{7}$ Selain itu, faktor kedekatan antar negara akan membuat akses penegakan HAM seyogyanya menjadi lebih mudah. Secara umum, gambaran tentang alasan negara-negara dalam membentuk mekanisme regional HAM dapat dirumuskan sebagai berikut:

(i) the existence of geographic, historical, and cultural bonds among States of a particular region; (ii) the fact that recommendations of a regional organization may meet with less resistance than those of a global body; (iii) the likelihood that publicity about human rights will be wider and more effective; 
(iv) the fact that there is less possibility of 'general, compromise formulae', which in global bodies are more likely to be based on 'considerations of a political nature'. ${ }^{8}$

Secara khusus di kawasan Asia Tenggara, tren upaya pembentukan mekanisme perlindungan HAM di tingkat regional juga dapat ditemukan setidaknya dalam lebih dari dua dekade terakhir. Konsultasi antar negara-negara ASEAN tentang isu HAM dimulai sejak bulan Juli 1993 dalam sebuah Joint Communiqué, yang menyepakati bahwa "ASEAN should consider the establishment of an appropriate regional mechanism on human rights." ${ }^{\prime 9}$ Adapun perjalanan panjang pembentukan mekanisme regional HAM di kawasan Asia Tenggara dapat diasumsikan karena tingginya keragaman antar negara-negara di kawasan, baik secara politis, kultur, maupun ekonomi. Keragaman ini secara langsung mengakibatkan perbedaan cara pandang antar negara terhadap kewajiban untuk melindungi HAM, dimana pada derajat tertentu, perbedaan ini menimbulkan resistensi negaranegara tertentu terhadap ancaman intervensi mekanisme regional dalam isu HAM. ${ }^{10}$ Dalam kaitannya dengan fenomena tersebut, Tommy Koh mengobservasi bahwa:

The ASEAN member states are divided into three groups on the issue of human rights: Indonesia, Malaysia, the Philippines and Thailand have national Human Rights Institutions and 'champion' human rights; Cambodia, Lao People's Democratic Republic (Lao), Myanmar and Vietnam are 'not enthusiastic'; and Brunei and Singapore are not in either camp but try to bridge the gap between the two. ${ }^{11}$

Berangkat dari observasi tersebut, dapat dipahami bahwa pada masa awal pembentukan mekanisme HAM regional Asia Tenggara, politik hukum HAM Indonesia pada prinsipnya sudah mengarah pada model perlindungan HAM yang maju secara institusional dalam konteks kawasan.

Upaya regionalisme HAM di bawah kerangka kerja ASEAN mencapai hasil yang signifikan ketika ASEAN Intergovernmental Commission on Human Rights (AICHR) terbentuk pada tahun 2009, yang kemudian Komisi ini berhasil merampungkan Deklarasi Hak Asasi Manusia ASEAN pada pertengahan tahun $2012 .{ }^{12}$ Adapun Deklarasi tersebut diadopsi oleh para kepala negara-negara ASEAN di Phnom Penh, Kamboja, pada 18 November 2012. Upaya regionalisme HAM tersebut merupakan salah satu langkah aksi bidang promosi dan perlindungan HAM yang tersurat dalam APSC blueprint, yang meliputi:

a. Establish an ASEAN human rights body through the completion of its Terms of

\footnotetext{
8 Commission to Study the Organization of Peace. 1980. Regional Promotion and Protection of Human Rights. Twety-Eighth Report of the Commission to Study the Organization of Peace, hlm. 15.

9 Joint Communique of the 26 ${ }^{\text {th }}$ ASEAN Ministerial Meeting, Singapura, 23-24 Juli 1993, paragraf 16-18.

10 Sebagai contoh: Lihat Suzannah Linton, "ASEAN States, Their Reservations to Human Rights Treaties and the Proposed ASEAN Commission on Women and Children", Human Rights Quarterly 30 (2008): 436-493, The Johns Hopkins University Press.

11 S. Petcharamesree, "The Human Rights Body: A Test for Democracy Building in ASEAN" (Stockholm: International Institute for Democracy and Electoral Assistance, 2009): 4.

12 Pasal 4.2 Terms of Reference the ASEAN Intergovernmental Commission on Human Rights menyebutkan bahwa, mandat Komisi untuk membentuk Deklarasi HAM ASEAN dengan pandangan untuk membangun kerangka kerja untuk kerjasama hak asasi manusia melalui berbagai konvensi ASEAN dan instrumen terkait hak asasi manusia.
} 
Reference (ToR) by 2009 and encourage cooperation between it and existing human rights mechanisms, as well as with other relevant international organizations;

b. Complete a stock-take of existing human rights mechanisms and equivalent bodies, including sectoral bodies promoting the rights of women and children by 2009;

c. Cooperate closely with efforts of the sectoral bodies in the development of an ASEAN instrument on the protection and promotion of the rights of migrant workers;

d. Strengthen interaction between the network of existing human rights mechanisms as well as other civil society organisations, with relevant ASEAN sectoral bodies;

e. Enhance/conduct exchange of information in the field of human rights among ASEAN countries in order to promote and protect human rights and fundamental freedoms of peoples in accordance with the ASEAN Charter and the Charter of the United Nations, and the Universal Declaration of Human Rights and the Vienna Declaration and Programme of Action;

f. Promote education and public awareness on human rights; and

g. Cooperate closely with efforts of the sectoral bodies in the establishment of an ASEAN commission on the promotion and protection of the rights of women and children.

\section{Politik Hukum HAM Nasional dalam Rezim HAM Regional}

Berdasarkan paparan historis regionalisme HAM di Asia Tenggara di atas, dapat diasumsikan bahwa secara ideal, harus terdapat harmoni dan kesinkronan antara mekanisme perlindungan HAM di tingkat internasional, regional, dan nasional. Penulis bahkan berpendapat bahwa norma dan nilai HAM yang disepakati di tingkat internasional (dalam hal ini baik mekanisme berbasis treaty maupun charter) perlu diimplementasikan ke dalam norma dan standar di tingkat domestik, sehingga tercipta kerangka perlindungan HAM yang linier dan bersifat universal. ${ }^{13}$ Walaupun patut dipahami pula bahwa, dalam temuan kuantitatif Neumayer, perjanjian HAM pada tingkat internasional tidak dapat serta-merta dapat dikatakan memperbaiki penghormatan terhadap HAM suatu negara. ${ }^{14}$ Lebih lanjut, Neumayer berpendapat bahwa:

On the one hand, in the absence of civil society and/or in pure autocracies, human rights treaty ratification often makes no difference and can even make things worse. .. [t]reaty ratification often becomes more beneficial to human rights the more democratic the country is. In addition, we also find evidence 
that ratification is more beneficial the stronger a country's civil society. ${ }^{15}$

Mengingat terdapat berbagai faktor yang memengaruhi relasi antara mekanisme perlidungan HAM internasional dan regional terhadap tingkat perlindungan HAM domestik, pada bagian ini penulis mencoba menerangkan bagaimana politik hukum HAM Indonesia seyogyanya berinter-relasi dengan regionalisme HAM ASEAN. Berangkat dari logika demikian, maka politik hukum HAM di Indonesia patut disiapkan dalam rangka memastikan berfungsinya rezim HAM regional ASEAN.

Secara normatif, politik HAM Pemerintah Indonesia telah digariskan dalam Rencana Aksi Nasional Hak Asasi Manusia (RANHAM) yang telah berjalan selama tiga fase lima tahunan sejak tahun $1998 .{ }^{16}$ Secara umum, terdapat beberapa program umum yang terdapat dalam tiap fase RANHAM, yang meliputi: (i) pembentukan panitia daerah dan pusat sebagai pelaksana rencana aksi, (ii) pendidikan HAM, (iii) ratifikasi perjanjian internasional, dan (iv) penerapan norma dan standar HAM. Pada tiap fase, perjalanan politik HAM nasional tersebut tidak selalu berjalan dengan mulus mengingat berbagai faktor yang memengaruhi pelaksanannya. Adapun persoalan utama yang kerap menjadi kendala dalam pelaksanaan program lima tahunan ini ialah pemahaman aparatur negara terkait tugas negara dalam melindungi dan memenuhi HAM. ${ }^{17}$ Fenomena tersebut menggambarkan pada kita bahwa trek birokratisasi RANHAM, dalam pengertian bahwa pelaksanaan rencana aksi dititikberatkan oleh aparatur negara, belum berjalan dengan maksimal. ${ }^{18}$

Dalam konteks tersebut, terdapat setidaknya tiga dimensi tantangan politik hukum HAM nasional Indonesia, yang meliputi: desentralisasi, militer, dan kerancuan penerapan hukum internasional.

Pada dimensi pertama, kebijakan desentralisasi yang berlaku saat ini belum menemukan formasi yang ideal, khususnya dalam rangka perlindungan HAM. Berdasarkan Undang-Undang Nomor 32 Tahun 2004 tentang Pemerintahan Daerah, jalur penghubung antara pemerintah pusat dengan pemerintah daerah diletakkan dalam bagian kewenangan Kementerian Dalam Negeri. Adapun Menteri Dalam Negeri dalam hal ini memiliki peran dalam pembinaan dan pengawasan pelaksanaan pemerintahan daerah, serta mengemban berbagai kewenangan terkait pengangkatan dan pemberhentian kepala daerah, pengawasan rancangan peraturan daerah dan peraturan daerah, dan lain sebagainya. ${ }^{19}$ Namun dalam

$5 \quad$ Ibid, hlm. 33.

16 Adapun dasar hukum pelaksanaan rencana aksi di tiga fase tersebut meliputi: Keputusan Presiden Nomor 129 Tahun 1998 tentang Rencana Aksi Nasional Hak Asasi Manusia yang kemudian diubah ke dalam Keputusan Presiden Nomor 61 Tahun 2003, Keputusan Presiden Nomor 40 Tahun 2004 tentang Rencana Aksi Nasional Hak Asasi Manusia Tahun 2004-2009, Peraturan Presiden Nomor 23 Tahun 2011 tentang Rencana Aksi Nasional Hak Asasi Manusia Tahun 2011-2014.

17 Lihat Penjelasan Peraturan Presiden Nomor 23 Tahun 2011 tentang Rencana Aksi Nasional Hak Asasi Manusia.

18 Evaluasi Bersama Pelaksanaan Rencana Aksi Nasional Hak Asasi Manusia tahun 2011-2014 oleh Badan Litbang HAM dan Direktorat Jenderal HAM tahun 2013 (tidak dipublikasikan).

19 Lihat Pasal 222 Undang-Undang Nomor 32 Tahun 2004 tentang Pemerintahan Daerah. 
mekanisme pelaksanaan RANHAM, Kementerian Dalam Negeri tidak berada pada posisi strategis yang dapat membuat (to impose) kebijakan agar lebih dapat secara efektif dilaksanakan oleh pemerintah daerah. ${ }^{20}$ Data kualitatif evaluasi yang pernah dilakukan menunjukkan bahwa tingkat 'kepatuhan' Panitia RANHAM Daerah akan lebih berpengaruh apabila perintah atau 'direktif' tentang RANHAM (dalam bentuk pedoman, petunjuk, permohonan, atau saran) diterbitkan oleh Kementerian Dalam Negeri ketimbang Kementerian Hukum dan HAM. Adapun dalam tataran praktik, 'direktif' tentang pelaksanaan RANHAM dari Kementerian Hukum dan HAM, dalam hal ini Direktorat Jenderal Hak Asasi Manusia, pada umumnya hanya berlaku secara efektif terhadap kegiatan Kantor Wilayah Kementerian Hukum dan HAM, sebagai instansi vertikal Kementerian Hukum dan HAM yang ada di masing-masing provinsi.

Mekanisme RANHAM yang sejalan dengan politik desentralisasi memberi dampak pula terhadap kemunculan tuntutan perlindungan nilai-nilai lokal pada masing-masing daerah. Tuntutan perlindungan nilai tersebut juga pada derajat tertentu menghendaki adanya pengesampingan terhadap hukum yang berlaku nasional oleh hukum adat setempat. Selain itu, dalam bungkus perlindungan nilai-nilai lokal, eksklusivitas antar daerah menjadi muncul ke permukaan sehingga menafikkan prinsip universal, keadilan, dan kesetaraan dalam HAM. Fenomena tersebut tentu dapat mengancam perlindungan HAM yang universal, selain juga memberikan potensi bagi terbitnya peraturan dan kebijakan masing-masing daerah yang diskriminatif. Sifat diskriminatif dalam hal ini mengacu pada semangat memunculkan nilai kedaerahan tertentu yang berpotensi bertolakbelakang dengan nilai masyarakat di daerah lainnya. ${ }^{21}$

Pada prinsipnya, mekanisme RANHAM merupakan sebuah forum yang dapat menjembatani antara amanat Undang-Undang Nomor 32 Tahun 2004 tentang Pemerintahan Daerah dengan amanat perlindungan HAM dalam Undang-Undang Nomor 39 Tahun 1999 tentang Hak Asasi Manusia. Secara lebih spesifik, mekanisme RANHAM seyogyanya dapat mengatasi kemunculan 'partikularisme' yang dapat mengancam mekanisme perlindungan HAM yang universal di seluruh Indonesia. Sejalan dengan Deklarasi Wina 1993, maka "while the significance of national and regional particularities and various historical, cultural and religious backgrounds must be borne in mind", negara tetap dalam posisi pengemban kewajiban untuk mempromosikan dan melindungi HAM dan kebebasan fundamental terlepas dari sistem politik, ekonomi, dan kulturalnya. Apabila diterapkan dalam mekanisme RANHAM saat ini, maka norma universalitas HAM tersebut harus 
mengalir dari Panitia RANHAM nasional ke tingkat daerah. Dengan demikian, kemunculan partikularitas dalam kerangka desentralisasi dapat diatasi melalui norma panduan (guiding norms) yang diterbitkan oleh pemerintah pusat untuk kemudian diikuti oleh pemerintah daerah.

Berangkat dari argumentasi tersebut, tulisan ini menyimpulkan bahwa pada dimensi pertama ini terdapat sebuah missing link mekanisme kerja Panitia RANHAM baik dari tingkat nasional sampai pada tingkat provinsi dan kabupaten/ kota. Dengan demikian, upaya penyesuaian mekanisme kerja Panitia RANHAM dengan mekanisme desentralisasi pemerintahan daerah justru menjadi salah satu kendala dalam pelaksanaan program yang tertera dalam kebijakan hukum tentang RANHAM.

Pada dimensi kedua, upaya reformasi sektor keamanan (RSK) yang belum menghasilkan cerminan perlindungan dan penegakan hukum HAM yang efektif, mengingat salah satu pihak yang menjadi sorotan utama sebagai aktor dalam pelanggaran HAM di Indonesia ialah aparat militer. Laporan yang diterbitkan oleh Komisi Nasional HAM misalnya, menyatakan bahwa pihak militer bertanggungjawab terhadap peristiwa penculikan aktivis Mei tahun 1998. ${ }^{22}$ Bahkan pada tahun 2013, peristiwa penembakan tahanan di Lapas Kelas IIA Yogyakarta oleh para anggota Koppasus mengisyaratkan terdapat personel militer yang belum sepenuhnya tanggap terhadap HAM. ${ }^{23}$ Perlu diakui bahwa pembenahan secara institusional di tubuh militer belum sepenuhnya dapat mengubah citra dan relasi politik militer dengan sipil. Studi yang dilakukan oleh Marcus Mietzner mengungkapkan gambaran reformasi sektor keamanan pada generasi kedua sebagai berikut:

Tabel 1. Second-Generation Reforms and Their Status in Indonesia ${ }^{24}$

\begin{tabular}{ll}
\multicolumn{1}{c}{ Reform } & \multicolumn{1}{c}{ Status } \\
\hline $\begin{array}{l}\text { Full government and parliamentary control over } \\
\text { military budget }\end{array}$ & Practice of partial military self-financing continues \\
\hline Effective auditing of military expenditure & $\begin{array}{l}\text { State auditors' authority to scrutinize military } \\
\text { budgets still very limited }\end{array}$ \\
\hline $\begin{array}{l}\text { Regular, interagency reassessment of threat situation } \\
\text { and military structure }\end{array}$ & $\begin{array}{l}\text { Threat assessment and force structure } \\
\text { determined by military elite }\end{array}$ \\
\hline $\begin{array}{l}\text { Transparent, credible military court system } \\
\text { Professional, multi-layered procurement } \\
\text { process of military equipment }\end{array}$ & $\begin{array}{l}\text { Public perception of impunity for military } \\
\text { personnel persists }\end{array}$ \\
\hline $\begin{array}{l}\text { Full adherence of the military bureaucracy } \\
\text { to executive decisions }\end{array}$ & $\begin{array}{l}\text { Network of military-connected agents still dominant; } \\
\text { corruption rampant }\end{array}$ \\
\hline Existence of vibrant civilian defense community & $\begin{array}{l}\text { Gradually improving, but remains dependant on the } \\
\text { loyalty of individual officers } \\
\text { to the president }\end{array}$ \\
\hline
\end{tabular}

22 Lihat Wacana HAM Edisi II/Tahun XI/2013, Komisi Nasional Hak Asasi Manusia.

23 Rilis liputan terkait berita ini dapat dilihat pada lama resmi Kompas http://lipsus.kompas.com/ topikpilihanlist/2410 (diakses 28 Agustus 2014).

24 Marcus Mietzner, The Politics of Military Reform in Post-Suharto Indonesia: Elite Conflict, Nationalism, and Institutional Resistance, (Washington: East-West Center, 2006), hlm. 63. 
Selain reformasi sektor keamanan pada struktur dan personel militer yang belum menunjukkan hasil yang maksimal, perspektif institusi politik terhadap kekuatan militer masih belum banyak bergerak dari perspektif terdahulu yang sudah lama tertanam dalam infrasturktur politik negara. Leonard Sebastian dan lisgindarsah menjelaskan bahwa:

[...] mindsets for civilian control are still not deeply rooted in Indonesia's democratic institutions, especially the parliament (DPR). The foremost obstacle in this regard is apathy, the unwillingness to develop expertise on defense matters, and the hesitation of many parliament members to carry out their constitutional resposibilites (Anggoro, 2002, pp. 1-22). The disregard of defense and military affairs by legislators is apparent in many cases, including their reluctance to participate in public discussions on defense and military issues coupled with a presumption that military expertise is the precondition to participate in defense policymaking. ${ }^{25}$

Dari kondisi demikian, maka politik hukum HAM Indonesia dapat dikatakan masih berada dalam bayang-bayang hegemoni militer, yang oleh sebab itu mengakibatkan beberapa hal, meliputi: pertama, pertanggungjawaban pidana pelanggaran berat HAM pada masa lalu masih akan menemukan jalan buntu; kedua, resistensi politik hukum HAM nasional terhadap intervensi mekanisme pemantauan internasional masih bertahan; dan ketiga, hambatan terhadap integrasi nilai dan prinsip HAM ke dalam praksis militer.

Selanjutnya pada dimensi ketiga, daftar ratifikasi instrumen internasional hak asasi manusia Negara Indonesia mencerminkan sebuah gambaran tentang pilihan politik Pemerintah Indonesia yang cenderung masih sangat berhati-hati dalam mengadopsi mekanisme intervensi HAM internasional (Tabel 2). Fenomena tersebut dapat dilihat dari absennya Negara Indonesia dalam perjanjian internasional yang memberikan otorisasi penegakan oleh lembaga judisial dan semijudisial, seperti:Protokol Pertama Opsionaluntuk Kovenan Internasional Hak Sipil dan Politik yang mengoperasionalkan Komite Hak Asasi Manusia, Protokol Opsional untuk Kovenan Internasional Hak Ekonomi, Sosial, dan Budaya yang memberi kewenangan pada Komite Hak Ekonomi, Sosial, dan Budaya, Protokol Opsional untuk Konvensi Anti Penyiksaan yang melandasi beroperasinya Sub-Komite pemantau penyiksaan, dan Statuta Roma tentang Mahkamah Pidana Internasional (lihat Tabel 3).

Daftar instrumen yang secara substansial mengoperasionalkan mekanisme intervensi semi-judisial di atas sesungguhnya sudah masuk ke dalam politik HAM pemerintah melalui program utama RANHAM. Namun, fakta bahwa sampai pada saat sekarang Negara Indonesia belum menjadi negara peserta mengisyaratkan bahwa secara politis, resistensi terhadap intervensi asing terkait pelaksanaan perindungan HAM domestik masih tinggi.

Ketiga dimensi tersebut merupakan sekelumit tantangan bagi politik HAM Indonesia tentang kesiapannya dalam kerangka kerja regionalisme HAM ASEAN. Ketiga dimensi tersebut perlu menjadi sorotan Indonesia 
Tabel 2. Status Ratifikasi Instrumen Hak Asasi Manusia Republik Indonesia ${ }^{26}$

\begin{tabular}{|c|c|c|c|}
\hline Treaty Description & Treaty Name & $\begin{array}{l}\text { Signature } \\
\text { Date }\end{array}$ & $\begin{array}{l}\text { Ratification Date, } \\
\text { Accession(a), } \\
\text { Succession(d) } \\
\text { Date }\end{array}$ \\
\hline $\begin{array}{l}\text { Convention against Torture and Other Cruel Inhuman or Degrading } \\
\text { Treatment or Punishment }\end{array}$ & CAT & $\begin{array}{l}23 \text { Oct } \\
1985 \\
\end{array}$ & 28 Oct 1998 \\
\hline Optional Protocol of the Convention against Torture & CAT-OP & & \\
\hline International Covenant on Civil and Political Rights & CCPR & & 23 Feb $2006(a)$ \\
\hline $\begin{array}{l}\text { Second Optional Protocol to the International Covenant on Civil and } \\
\text { Political Rights aiming to the abolition of the death penalty }\end{array}$ & CCPR-OP2-DP & & \\
\hline $\begin{array}{l}\text { Convention for the Protection of All Persons from Enforced } \\
\text { Disappearance }\end{array}$ & CED & $\begin{array}{l}27 \text { Sep } \\
2010 \\
\end{array}$ & \\
\hline $\begin{array}{l}\text { Convention on the Elimination of All Forms of Discrimination against } \\
\text { Women }\end{array}$ & CEDAW & 29 Jul 1980 & 13 Sep 1984 \\
\hline $\begin{array}{l}\text { International Convention on the Elimination of All Forms of Racial } \\
\text { Discrimination }\end{array}$ & CERD & & 25 Jun 1999 (a) \\
\hline International Covenant on Economic, Social and Cultural Rights & CESCR & & 23 Feb 2006 (a) \\
\hline $\begin{array}{l}\text { International Convention on the Protection of the Rights of All Migrant } \\
\text { Workers and Members of Their Families }\end{array}$ & CMW & $\begin{array}{l}22 \text { Sep } \\
2004 \\
\end{array}$ & 31 May 2012 \\
\hline Convention on the Rights of the Child & CRC & 26 Jan 1990 & 05 Sep 1990 \\
\hline $\begin{array}{l}\text { Optional Protocol to the Convention on the Rights of the Child on the } \\
\text { involvement of children in armed conflict }\end{array}$ & CRC-OP-AC & \begin{tabular}{|l|}
24 Sep \\
2001 \\
\end{tabular} & 24 Sep 2012 \\
\hline $\begin{array}{l}\text { Optional Protocol to the Convention on the Rights of the Child on the } \\
\text { sale of children child prostitution and child pornography }\end{array}$ & CRC-OP-SC & $\begin{array}{l}24 \text { Sep } \\
2001\end{array}$ & 24 Sep 2012 \\
\hline Convention on the Rights of Persons with Disabilities & CRPD & $\begin{array}{l}30 \text { Mar } \\
2007\end{array}$ & 30 Nov 2011 \\
\hline
\end{tabular}

Tabel 3. Status penerimaan Republik Indonesia terhadap prosedur individual complaints ${ }^{27}$

\begin{tabular}{l|l|l}
\hline \multicolumn{1}{c|}{ Treaty Description } & \multicolumn{1}{c}{$\begin{array}{c}\text { Treaty } \\
\text { Name }\end{array}$} & $\begin{array}{c}\text { Acceptance } \\
\text { of individual } \\
\text { complaints } \\
\text { procedures }\end{array}$ \\
\hline Individual complaints procedure under the Convention against Torture & CAT, Art.22 & N/A \\
\hline Optional Protocol to the International Covenant on Civil and Political Rights & CCPR-OP1 & NO \\
\hline $\begin{array}{l}\text { Individual complaints procedure under the International Convention for the } \\
\text { Protection of All Persons from Enforced Disappearance }\end{array}$ & CED, Art.31 & - \\
\hline $\begin{array}{l}\text { Optional Protocol to the Convention on the Elimination of All Forms of Discrimination } \\
\text { against Women }\end{array}$ & CEDAW-OP & NO \\
\hline $\begin{array}{l}\text { Individual complaints procedure under the International Convention on the } \\
\text { Elimination of All Forms of Racial Discrimination }\end{array}$ & $\begin{array}{l}\text { CERD, } \\
\text { Optional protocol to the International Covenant on Economic, Social and Cultural } \\
\text { Rights }\end{array}$ & CESCR-OP \\
\hline $\begin{array}{l}\text { Individual complaints procedure under the International Convention on the } \\
\text { Protection of the Rights of All Migrant Workers and Members of Their Families }\end{array}$ & NO \\
\hline Optional Protocol to the Convention on the Rights of the Child & Art.77 & N/A \\
\hline Optional protocol to the Convention on the Rights of Persons with Disabilities & CRC-OP-IC & NO \\
\hline
\end{tabular}

26 Data diolah dari laman resmi Kantor Komisioner Tinggi HAM PBB, dapat diakses pada: http://tbinternet.ohchr. org/SitePages/Home.aspx

27 Ibid. 
pada masa sekarang guna memastikan kompatibilitas atau kesesuaian serta kepatuhan politik hukum HAM domestik terhadap norma HAM internasional, serta guna mempertegas universalitas perlindungan HAM di tingkat regional. Terkait hal tersebut, secara lebih spesifik dari sudut pandang 'republikan-liberal', yang memandang komitmen negara untuk turut serta dalam sebuah rezim HAM sebagai sebuah hasil kalkulasi politik dalam negeri, penulis beranggapan bahwa politik hukum HAM domestik Indonesia perlu mendudukkan regionalisme HAM ASEAN sebagai cerminan kepentingan nasional untuk mengurangi ketidakpastian politik domestik. Moravcsik menjelaskan lebih lanjut pandangan ini:

From this perspective, human rights norms are expressions of the self-interest of democratic governments in "locking in" democratic rule through the enforcement of human rights. By placing interpretation in the hands of independent authorities managed in part by foreign governments - in other words, by alienating sovereignty to an international body-governments seek to establish reliable judicial constraints on future nondemocratic governments or on democratically elected governments that may seek (as in interwar Italy and Germany) to subvert democracy from within. ${ }^{28}$

Dari logika tersebut, sesungguhnya dalam regionalisme HAM ASEAN yang ada, terdapat kepentingan nasional Bangsa Indonesia yang perlu diperjuangkan, yakni: tidak hanya untuk memastikan dan mengembangkan perlindungan HAM domestik, namun juga untuk menjamin keberlanjutan kehidupan demokrasi Indonesia melalui pemantauan otoritas independen HAM di tingkat regional Asia Tenggara.

\section{Memastikan Perlindungan HAM dalam Regionalisme HAM ASEAN}

Setelah menganalisis deskripsi serta tantangan politik HAM Indonesia, pada bagian ini penulis mencoba menjabarkan interaksi antara mekanisme perlindungan HAM regional di bawah rezim AICHR dengan perlindungan HAM domestik. Secara khusus, perhatian akan diarahkan terutama pada bagaimana regionalisme HAM ASEAN melalui institusi AICHR seyogyanya dapat mendorong kepatuhan HAM internasional (international human rights compliance) Negara Indonesia, serta bagaimana pada sisi yang lain, mekanisme kerja perlindungan HAM Indonesia dapat mewarnai perlindungan HAM di tingkat regional. Terhadap pertanyaan tersebut, analisis pertama-tama perlu ditujukan pada alas normatif kerja AICHR, mengingat efektivitas perlindungan HAM secara institusional tidak dapat terlepas dari kerangka hukum yang mendasari tugas AICHR.

Pasal 4 ToR menyebutkan mandat dan fungsi AICHR meliputi:

a. To develop strategies for the promotion and protection of human rights and fundamental freedoms to complement the building of the ASEAN Community;

b. To develop an ASEAN Human Rights Declaration with a view to establishing a framework for human rights cooperation through various ASEAN conventions and other instruments dealing with human rights;

c. To enhance public awareness of human rights among the peoples of ASEAN through education, research and dissemination of information;

Moravscik, Ibid, hlm 228. 
d. To promote capacity building for the effective implementation of international human rights treaty obligations undertaken by ASEAN Member States;

e. To encourage ASEAN Member States to consider acceding to and ratifying international human rights instruments;

f. To promote the full implementation of ASEAN instruments related to human rights;

g. To provide advisory services and technical assistance on human rights matters to ASEAN sectoral bodies upon request;

h. To engage in dialogue and consultation with other ASEAN bodies and entities associated with ASEAN, including civil society organizations and other stakeholders, as provided for in Chapter $V$ of the ASEAN Charter;

i. To consult, as may be appropriate, with other national, regional and international institutions and entities concerned with the promotion and protection of human rights;

i. To obtain information from ASEAN Member States on the promotion and protection of human rights;

k. To develop common approaches and positions on human rights matters of interest to ASEAN;

I. To prepare studies on thematic issues of human rights in ASEAN;

$m$. To submit an annual report on its activities, or other reports if deemed necessary, to the ASEAN Foreign Ministers Meeting; and

n. To perform any other tasks as may be assigned to it by the ASEAN Foreign Ministers Meeting.
Pembacaan terhadap pasal tersebut mengindikasikan bahwa negara-negara pihak ASEAN telah membentuk sebuah rezim HAM regional yang cenderung bersifat promosional. Adapun berdasarkan teoresasi Jack Donelly tentang rezim perlindungan HAM internasional, sifat promosional kemudian dibagi kembali ke dalam dua sifat, yakni promosional kuat (strong promotional) dan promosional lemah (weak promotional). ${ }^{29}$ Berdasarkan mandat dan fungsi AICHR yang ada, maka posisi AICHR sebagai mekanisme regional berada dalam sifat promosional lemah, dimana kekuatan implementasi atau domestikasi norma HAM dari tingkat AICHR ke negara-negara pihak masih dalam posisi lemah.

Dengan kondisi demikian, maka regionalisme HAM 'promosional lemah' (weak promotional) yang coba dibentuk oleh negara-negara ASEAN perlu mendapatkan formulasi ulang utamanya untuk memastikan efektivitas fungsi mekanisme perlindungan HAM regional. Pada titik ini, secara praktis politik HAM Indonesia perlu memerhatikan beberapa pertimbangan strategis sebagai berikut:

a. The most effective institutions for international human rights enforcement rely on prior sociological, ideological and institutional convergence toward common norms;

b. The lack of international consensus, rather than the weakness of international institutions, generally imposes the binding constraint on international human rights enforcement;

29 Lihat Jack Donelly, "International Human Rights: A Regime Analysis”. International Organization 40, 3, Summer, (1986): 599-642. 
c. While awaiting the development of a system of supranational adjudication, more promising strategies may be to strengthen domestic civil society and political institutions, and to strengthen traditional international organizations that gather information and arrange consultations. ${ }^{30}$

Berdasarkan strategi tersebut, maka penguatan civil society dan lembaga politik pada tingkat domestik merupakan keharusan, sebagai prakondisi bagi terbentuknya mekanisme ajudikasi supranasional pada tingkat regional Asia Tenggara. Indonesia dengan demikian perlu mempertimbangkan penguatan partisipasi civil society dalam pelaksanaan politik HAM nasional, terlepas bagaimanapun format politik HAM domestik Indonesia pada waktu yang akan datang. Dengan penguatan partisipasi civil society dan lembaga politik pada tingkat domestik, regionalisme HAM ASEAN diharapkan dapat terdorong untuk bergerak dari rezim promosional lemah menuju ke kuadran rezim implementasional, untuk kemudian secara bertahap menjadi rezim penegakan HAM regional.

Kekurangan utama dari rezim promosional lemah AICHR ialah kapasitas institusional yang tidak lagi relevan untuk menjawab tantangan perkembangan perlindungan HAM masa kini. Walaupun pembentukan AICHR, sebagai ujung tombak perlindungan HAM dalam kerangka kerja ASEAN, merupakan langkah yang signifikan dalam hubungan regional negara-negara ASEAN, namun dari sisi institusional Komisi ini tidak mencerminkan sebuah 'keorganisasian HAM' (human rights organizationhood) yang efektif. Pemberian mandat promosional yang ada tersebut dapat pula diasumsikan sebagai cerminan politik domestik di masing-masing negara anggota ASEAN yang cenderung mempertahankan kedaulatan teritorial masing-masing negara, sehingga pada banyak kesempatan, negara-negara anggota berlaku enggan dan curiga terhadap setiap mekanisme pemantauan (maupun penegakan) HAM pada level regional dan internasional. ${ }^{31}$

Dari perspektif hukum organisasi internasional, agar dapat bekerja secara efektif, maka setidaknya keorganisasian HAM harus memiliki kewenangan dalam hal policy coordination dan legal enforcement terhadap negara-negara pihak. ${ }^{32}$ Kedua hal tersebut dapat dianggap sebagai distinct will dari sebuah organisasi HAM internasional, dalam arti bahwa sebuah organisasi HAM yang dibentuk antar negara wajib memiliki keinginan atau tujuan yang berbeda dengan yang dimiliki oleh negaranegara anggota yang bersangkutan. ${ }^{33}$ Dalam hal ini, maka pembentukan rezim HAM AICHR seharusnya sejalan dengan mandat Pasal 14 (1) ASEAN Charter yang mengatur, "In conformity with the purposes and principles of the ASEAN 
Charter relating to the promotion and protection of human rights and fundamental freedoms, ASEAN shall establish an ASEAN human rights body." Secara eksplisit dalam pasal tersebut disebutkan bahwa pembentukan badan HAM ASEAN perlu didasarkan pada prinsip ASEAN yang memiliki kaitan dengan promosi dan perlindungan HAM. Adapun melalui ToR AICHR, dapat diasumsikan bahwa penerjemahan terhadap prinsip ASEAN yang dimaksud meliputi: a) respect for the independence, sovereignty, equality, territorial integrity and national identity of all ASEAN Member States; b) non-interference in the internal affairs of ASEAN Member States; c) respect for the right of every Member State to lead its national existence free from external interference, subversion and coercion; d) adherence to the rule of law, good governance, the principles of democracy and constitutional government; e) respect for fundamental freedoms, the promotion and protection of human rights, and the promotion of social justice; f) upholding the Charter of the United Nations and international law, including international humanitarian law, subscribed to by ASEAN Member States; dan g) respect for different cultures, languages and religions of the peoples of ASEAN, while emphasising their common values in the spirit of unity in diversity.

Namun demikian, apabila dikaitkan dengan 'human rights organizationhood' yang telah disebutkan sebelumnya, maka sebenarnya pencantuman prinsip non-interference in the internal affairs of ASEAN Member States menjadi sia-sia, karena sebuah rezim HAM yang efektif akan melakukan intervensi terhadap kedaulatan masing-masing negara pihak. Adapun bentukbentuk dari intervensi tersebut pada prinsipnya memiliki keragaman yang dapat dinilai sebagai soft power intervention maupun hard power intervention. Soft power intervention yang mungkin dilakukan oleh rezim HAM ASEAN meliputi: pemantauan dan koordinasi kebijakan. Sedangkan hard power intervention dapat diterjemahkan ke dalam kewenangan seperti pemberian sanksi secara hukum.

Penulis beranggapan bahwa pilihan rasional bagi negara-negara ASEAN terkait dengan pergeseran sifat rezim AICHR ialah dengan memberi kewenangan menuju ke rezim implementasi dengan mandat soft intervention. $^{34}$ Menurut hemat penulis, kewenangan rezim penegakan HAM dengan hard power intervention secara politis belum mendapat tempat yang strategis di kawasan ASEAN, mengingat pola interaksi antar negara yang cenderung menutup tirai kedaulatan ketika isu HAM sedang mengemuka. Secara lebih praktis, soft intervention dalam ASEAN perlu diarahkan ke dalam bentuk pemantauan internasional dan koordinasi kebijakan, yang dapat diartikan sebagai berikut:

a. International monitoring: formal international review of state practice but no authoritative enforcement procedures. Monitoring activities can be further categorized in terms of the powers allowed to monitors to carry out independent investigations and make judgments of compliance with international norms.

34 Lihat. Jack Donnelly, Ibid. Donnelly lebih lanjut menjelaskan bahwa: "International implementation activities include weaker monitoring procedures, policy coordination, and some forms of information exchange." hlm. 604 . 
b. International policy coordination: regular and expected use of an international forum to achieve greater coordination of national policies but no significant international review of state practice. ${ }^{35}$

Secara legal, pergeseran sifat rezim AICHR menuju rezim implementasi tidak melanggar dasar-dasar normatif yang tertera dalam ASEAN Charter. Rezim yang demikian justru dapat memperkuat dan mempertegas posisi AICHR dalam memastikan kepatuhan hukum negaranegara anggota ASEAN terhadap komitmen dalam perlindungan HAM di regional. Melalui fungsi pemantauan dan koordinasi kebijakan, dengan demikian AICHR akan memiliki memiliki kewenangan untuk dapat memengaruhi serta membentuk prilaku HAM negara-negara ASEAN. Lebih lanjut, pergeseran sifat rezim tersebut juga dapat mendorong terciptanya komunitas keamanan dan politik yang kuat di kawasan Asia Tenggara, sebagaimana dicita-citakan dalam naskah blueprint APSC. Selain itu, argumentasi tersebut secara teoretis mendapatkan justifikasi bahwa negara-negara dengan tingkat perlindungan HAM yang tinggi, serta menjujung the rule of law, akan cenderung menahan diri untuk berkonflik satu dengan yang lain. ${ }^{36}$

Sejalan dengan logika usulan pergeseran sifat rezim di atas, pada level domestik, politik HAM nasional Indonesia juga perlu direposisikan agar sejalan dengan proposal paradigma regionalisme HAM ASEAN tersebut. Kepatuhan (compliance) Negara Indonesia terhadap norma internasional melalui politik HAM nasional tentu memiliki kaitan dengan berbagai aspek di tingkat domestik. Dari perspektif teori 'new liberal', Kingsbury melihat kepatuhan:

..involves conformity with different sets of norms made by and directed to different sets of actors, rather than the traditional model of inter-state rules implemented by national measures. Appropriate levels of compliance, and perhaps even the meaning of "compliance," are outcomes of the political interaction of aggregated preferences or, in discursive accounts, the weighted claims and responses of the relevant actors in the discursive community. ${ }^{37}$

Beranjak dari dimensi tantangan yang telah disebutkan pada sub-bagian (2) di atas, maka politik hukum HAM Indonesia perlu memperhatikan tantangan-tantangan tersebut guna menghadapi rezim implementasional ASEAN. Pada aspek politik desentralisasi, peran gubernur perlu diperkuat dalam memastikan kebijakan dan arah politik HAM nasional sehingga diterjemahkan secara utuh di tingkat provinsi, kabupaten, dan kota. Apabila mengacu pada format kepanitiaan RANHAM yang sudah ada, maka pemangkasan birokratisasi pelaksanaan program RANHAM merupakan langkah yang mutlak diperlukan. Seiring dengan pemangkasan birokratisasi kepanitiaan tersebut, maka tiap gubernur perlu mendapatkan peran 
lebih dalam mengimplementasikan politik hukum HAM nasional di masa mendatang pada tingkat daerah. Idealnya, politik hukum HAM nasional merupakan pengejawantahan dari norma dan prinsip HAM yang telah disepakati pada tingkat internasional dan regional. Dalam rangka penyelarasan norma dan prinsip tersebut, maka gubernur perlu mengambil peran yang signifikan dalam pelaksanaan politik hukum HAM nasional. Kerancuan yang selama ini terjadi ialah fenomena banyaknya jumlah pembentukan panitia RANHAM pada tingkat provinsi dan kabupaten/kota, yang justru memperumit mekanisme kerja pelaksanaan program RANHAM.

Selain dari aspek institusional, secara substansial politik hukum HAM nasional perlu diarahkan pada mendorong terwujudnya good governance dalam pemerintahan serta memaksimalkan partisipasi publik. Penguatan dimensi HAM pada dua substansi tersebut merupakan prasyarat mutlak bagi Indonesia dalam menyongsong APSC di tahun 2015, sekaligus secara luas menjadi prasyarat ditingkat domestik bagi berfungsinya rezim mekanisme HAM regional yang bersifat implementasional.

\section{Penutup}

Deskripsi tentang kritik dan tantangan terhadap politik hukum HAM nasional dan rezim mekanisme HAM regional ASEAN melalui kerangka kerja AICHR di atas merupakan salah satu aspek legal yang perlu diperhatikan dalam rangka mendorong perlindungan dan promosi HAM yang lebih maju, baik pada tingkat nasional maupun regional. Oleh sebab itu, harmoni dalam reposisi politik hukum HAM baik di tingkat nasional dan regional tentunya sangat diperlukan, agar norma yang telah disepakati pada tingkat internasional dapat diimplementasikan dan diterjemahkan ke dalam regionalisme HAM, dan yang lebih penting lagi ialah, agar regionalisme HAM ASEAN dapat memberi pengaruh terhadap tingkat domestikasi nilai dan prinsip HAM secara nasional di Indonesia.

Berdasarkan analisis pada rezim AICHR yang ada, maka Indonesia perlu mendorong adanya pegeseran sifat rezim dari promosional menuju ke implementatif, dimana perlu dilakukan penambahan mandat AICHR berupa pemantauan regional dan koordinasi kebijakan antar negara-negara anggota. Dengan pergeseran sifat rezim tersebut, diharapkan tingkat kepatuhan negara-negara anggota terhadap kewajiban dalam hukum HAM internasional akan menjadi lebih maksimal. Oleh sebab itu, sejalan dengan pembaruan tersebut pula, pada tingkat domestik politik hukum HAM Indonesia perlu memperhatikan tiga isu penting yang meliputi: perbaikan kebijakan desentralisasi, perwujudan militer nasional yang profesional, dan memastikan pelaksanaan kewajiban dalam hukum HAM internasional.

\section{DAFTAR PUSTAKA}

\section{Buku}

ASEAN Political-Security Community Blueprint, (Jakarta: ASEAN Secretariat, June 2009).

Keohane, R. and Joseph S. Nye. Power and Interdependence: World Politics in Transition. (Boston: Little, Brown, 1977).

Mietzner, Marcus., The Politics of Military Reform in Post-Suharto Indonesia: Elite Conflict, Nationalism, and Institutional Resistance, (Washington: East-West Center, 2006).

Petcharamesree, S. The Human Rights Body: A Test for Democracy Building in ASEAN. (Stockholm: International Institute for Democracy and Electoral Assistance, 2009).

Makalah/Artikel/Prosiding/Hasil Penelitian 
Citrawan, Harison. ASEAN Human Rights Regime: Reciprocity or Common Interest? (Jakarta: The Jakarta Post, 8 Agustus 2012).

Donelly, J. "International Human Rights: A Regime Analysis", International Organization 40, 3, Summer, (1986).

Hegre, Håvard. ]Democracy and Armed Conflict? Journal of Peace Research Vol. 51(2), Sage Publication (2014).

Kingsbury, Benedict. "The Concept of Compliance as A Function of Competing Conceptions of International Law", Michigan Journal of International Law Vol.19:345, (1998)

Moravcsik, A. "Explaining International Human Rights Regimes: Liberal Theory and Western Europe", European Journal of International Relation. SAGE London, Thousand Oaks, CA and New Delhi, Vol 1 (2), (1995).

Moravcsik, Andrew. "The Origins of Human Rights Regimes: Democratic Delegation in Postwar Europe", International Organization 54, 2 (2000). Nugroho, Bhakti Eko. After Three Years of the AICHR: What is Next?, dipresentasikan pada Konferensi the ICIRID (2013).
Saunders, Pammela Q. "The Integrated Enforcement of Human Rights", International Law and Politics Vol.45:97 (2012).

Sebastian, Leonard C. dan lisgindarsah. "Taking Stock of Military Reform in Indonesia", dalam J. Rúland et al. (eds.), The Politics of Military Reform, Global Power Shift, Springer-Verlag Berlin Heidelberg (2013).

Tan, Hsien-Li. The ASEAN Intergovernmental Commission on Human Rights: Institutionalizing Human Rights in Southeast Asia. Cambridge University Press. New York (2011).

\section{Internet}

Kidanemariam, FekadeselassieF. 2006. “Enforcement of Human Rights under Regional Mechanisms: a Comparative Analysis", LLM Theses and Essays. Paper 80. http://digitalcommons.law.uga.edu/ $\mathrm{stu} \_l \mathrm{~m} / 80$

Neumayer, Eric. Do International Human Rights Treaties Improve Respect for Human Rights? [online] London: LSE Research Online; http:// eprints.Ise.ac.uk/archive/00000612, diakses pada 24 Juni 2014. 